\title{
Exploration of exact significance of lymph node ratio and construction of a novel stage in colon cancer with no distant metastasis
}

This article was published in the following Dove Press journal: Cancer Management and Research

\author{
Yang $L v^{l}, *$ \\ Qing-Yang Feng ${ }^{1} * *$ \\ Song-Bin $\operatorname{Lin}^{2, *}$ \\ Yi-Hao Maol,* \\ Yu-Qiu Xu' \\ Peng Zheng' \\ Liang-Liang Yang ' \\ Guo-Dong $\mathrm{He}^{\prime}$ \\ Jian-Min $X u^{\prime}$
}

'Department of General Surgery,

Zhongshan Hospital, Fudan University,

Shanghai 200032, People's Republic of

China; ${ }^{2}$ Department of General Surgery,

Zhongshan Hospital Xiamen Branch,

Fudan University, Xiamen city, People's

Republic of China

*These authors contributed equally to this work

\begin{abstract}
Aim: Lymph node ratio (LNR) seems to be more precise than classic $\mathrm{N}$ stage in classifying cancer stage. Thus, we aim to construct a modified classification system based on LNR for colon cancer without distant metastasis.

Methods: This study enrolled two independent cohorts of patients. The primary cohort enrolled 2,152 patients from 2008 to 2013 in Zhongshan Hospital, Fudan University. The validation cohort consisted of 77,406 patients from the Surveillance, Epidemiology, and End Results (SEER) registry from 2004 to 2014. The inclusion criteria were: pathologically confirmed colon cancer, and American Joint Committee on Cancer (AJCC) stage I/II/III. The exclusion criteria included: incomplete follow-up information, rectal cancer, and multiple primary sites. The prognostic value of LNR for overall survival was evaluated. The cutoff value of LNR was determined by the X-tile. Predictive performance of modified classification was determined by the concordance index.

Results: After analysis, 0.05 and 0.50 were determined as the best threshold values of LNR. A value of $<0.05,0.05-0.50$ and $>0.50$ was reclassified as the $\mathrm{mN} 0, \mathrm{mN} 1$ and $\mathrm{mN} 2$ stage. A modified classification based on $\mathrm{mN} 0, \mathrm{mN} 1$, and $\mathrm{mN} 2$ was further constructed for stage $\mathrm{I} / \mathrm{II} / \mathrm{III}$ colon cancer. $\mathrm{C}$-index of the modified classification was statistically more precise than AJCC classification $(0.687$ versus $0.605, P<0.001)$. The same results can also be determined in the validation cohort $(0.715$ versus $0.640, P<0.001)$. Furthermore, a prognostic nomogram including independent factors was constructed. The constructed nomogram showed good performance according to the calibration curve.
\end{abstract}

Conclusion: The clinical value of LNR level was preferable to classic N stage in colon cancer patients. Our proposed classification based on LNR and AJCC T category can effectively differentiate patients with varied survival outcomes.

Keywords: colon cancer, prognosis, lymph node ratio, modified stage, nomogram

\section{Introduction}

Colon cancer, as one of the most common malignancies in the digestive gastrointestinal tract, ${ }^{1}$ accounts for one-third of the estimated new digestive cancer cases. ${ }^{2}$ For colon cancer, positive histological confirmation of American Joint Committee on Cancer (AJCC) stage is a significant indicator in managing the next therapeutic strategy. ${ }^{3}$ However, classification of $\mathrm{N}$ stage (namely lymph node metastasis status) depends on the resection range of surgical procedure and circumspective examination of pathologists, which may lead to inevitable bias and major error in evaluating merely the positivity of lymph node metastasis. The false-negative nodal staging
Correspondence: Jian-Min Xu;

Guo-Dong He

Department of General Surgery,

Zhongshan Hospital, Fudan University,

I80 Fenglin Road, Shanghai 200032,

People's Republic of China

Tel +86 2164041990

Fax +86 2164041990

Email xujmin@aliyun.com;

angelhgd@I63.com 
caused by inadequacy of lymph node retrieval exists in AJCC stage I-III colon cancer on a broad scale.

Lymph node ratio (LNR), first reported by Berger in $2004,{ }^{4}$ is defined as the number of positive lymph nodes (PLNs) divided by the total examined lymph nodes. LNR has been reported ${ }^{5-8}$ many times to be a robust predictor of survival, better than traditional $\mathrm{N}$ stage; therefore, the specific clinical advantage of LNR with respect to nonTNM factors such as age, differentiation grade, has still not been explored in colon cancer patients with a population-based scale. ${ }^{9}$ Many reports have studied the clinical value of LNR by only focusing on stage III colon cancer (with lymph node metastasis) and demonstrated that LNR has no clinically prognostic power to differentiate Stage I and Stage II (colon cancer patients with no lymph node metastasis). ${ }^{10}$ However, according to the current AJCC classification on colon cancer, the same $\mathrm{T}$ categories with or without lymph node metastasis were considered as different prognosis groups, even in selective patients with a low value of LNR (such as 1 PLN of 99 examined lymph nodes). It may be assumed that such patients would be considered to have a preferable prognosis compared to non-lymph node metastasis patients. Thus, the specific prognostic stratification of these patients should be further reclassified.

Thus, in this study, we use data retrieved from a large Chinese center to identify good cutoff values of LNR affecting survival and to construct a modified stage for prognosis prediction in colon cancer patients with no distant metastasis. The capability of the constructed model was further determined through the validation of Surveillance, Epidemiology, and End Results (SEER) registry performed to determine the specific prognostic capability. In addition, a novel nomogram including LNR breaking through the traditional TNM system should be established to assist in chemotherapy risk stratification and survival predictor precisely.

\section{Methods and materials \\ Patients and data resources}

This study was approved by the ethics committee of Zhongshan Hospital, Fudan University, and informed written consent was obtained for each patient. For the primary cohort, the clinical data of 2,152 colon cancer patients without distant metastasis at Zhongshan Hospital between January 2008 and December 2013 were derived from the single-institutional database. Patients with colon adenocarcinoma, mucinous adenocarcinoma, and signet-ring cell carcinoma were included in this study. Patients with multiple primary cancer, preoperative adjuvant therapy and missing follow-up information were excluded (Figure 1). All cancers were described in the study according to the TNM Classification of Malignant Tumors, eighth edition (TNM 8th).

For the validation cohort, data of patients with colon cancer (site code C18.2 - Ascending colon, C18.3 Hepatic flexure of colon, C18.4 - Transverse colon, C18.5 - Splenic flexure of colon, C18.6 - Descending colon, C18.7 - Sigmoid colon and C18.8 - Overlapping lesion of colon) diagnosed from 2004 to 2014 were retrieved from SEER database. The following International Classification of Diseases for oncology, third edition (ICD-O-3rd) histology codes were used to determine colon cancer: carcinoma (8010/3) and adenocarcinoma (8140/3). All the diagnoses were made through the positive histological examination, and data of unresectable patients were excluded. Other data containing age at diagnosis, sex, date of initial diagnosis, tumor differentiation, location of distant metastasis and cancer-specific survival (CSS) were retrieved from databases. For the evaluation of AJCC 8th edition TNM stage was performed basing on the following codes: collaborative stage (CS) tumor size 2004, CS metastases at DX 2004, CS lymph nodes 2004 and derived AJCC stage group (7th edition). Colon cancer patients with unknown characteristics or lacking survival information were excluded in our study. After the retrieval process, data of 122,227 colon cancer patients were retrieved from the SEER database; the re-evaluation of AJCC stage based on tumor size, distant metastases and lymph nodes metastasis. Of 122,227 patients, 77,406 colon cancer patients without distant metastasis were retrieved from the database.

\section{Statistical analysis}

Statistical analyses were performed using the SPSS statistical package. The chi-squared test and Fishers exact test were used to compare proportions when appropriate, whereas means were compared using a nonparametric test. Pearson correlation and nonlinear exponential regression analysis were also carried out. Overall survival (OS) analyses were carried out using the Kaplan-Meier method, and the results were compared using a log-rank test. A multivariable Cox proportional hazards model predicting OS was performed using backward stepwise selection. Risk factors were expressed as [HR, 95\%CI]. Statistical significance was defined as $P$-value less than 0.05 . The 

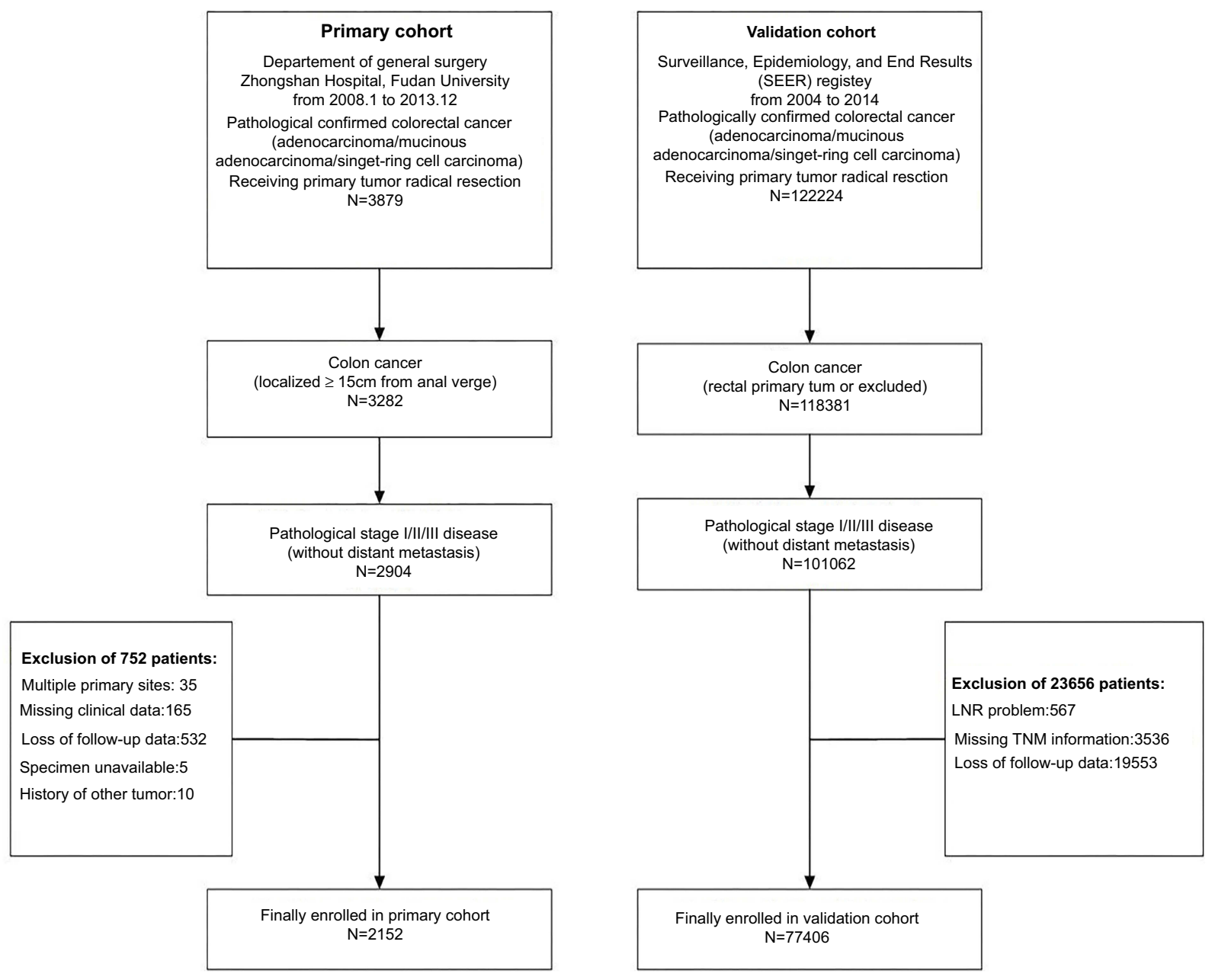

Figure I Flow diagram of stage IIIIIII colon cancer patients enrolled from our institution and the SEER database. Abbreviations: LNR, lymph node ratio; SEER, surveillance, epidemiology, and end results.

cutoff value of the LNR was determined by the X-tile (3.6.1, Yale University) from the primary cohort patients with all ranges of LNR data. The predictive nomogram was formulated on the basis of a multivariate analysis using the package of rms in $\mathrm{R}$ version 3.3.0. The validation and discrimination of the nomogram were determined by the Harrell concordance index (C-index) as an index of model performance. Higher $\mathrm{C}$-index values indicate better discrimination.

\section{Results}

\section{Clinicopathological characteristics of colon cancer cases}

The flow diagram of cohort selection is shown in Figure 1. For the primary cohort, 2,152 patients with stage I $\backslash I I \backslash I I I$ colon cancer were included (Table 1). Approximately $33.69 \%$ of patients had a tumor located at the sigmoid colon. More than $90 \%$ of patients had poor and intermediate differentiated tumors. The median survival time was 50.0 months (5-year survival rate, $37.77 \%$ ). The median follow-up period was 83.2 months (range 1.3-124.5 months). For the validation cohort, the clinical data of 122,224 colon cancer patients diagnosed with histologically confirmed colon cancer were retrieved from the SEER database from 2004 to 2014 . In total, 77,406 patients with stage I $\backslash$ II III colon cancer were included in this study, and the baseline characteristics are shown in Table 1. The median age at the year of diagnosis was 68 (ranging from 11 to 85$)$. The primary site of colon cancer was the sigmoid colon $(38.89 \%)$. For the differentiation grade of the primary site, approximately $7.10 \%$, $74.43 \%, 16.60 \%$ and $1.87 \%$ of colon cancer patients suffered from well, moderate, poor and nonneoplastic differentiations, respectively. 
Table I Baseline clinical characteristics

\begin{tabular}{|l|l|l|l|l|}
\hline \multirow{2}{*}{ Characteristics } & \multicolumn{2}{l|}{$\begin{array}{l}\text { Primary } \\
\text { cohort }\end{array}$} & \multicolumn{2}{l|}{$\begin{array}{l}\text { Validation } \\
\text { cohort }\end{array}$} \\
\cline { 2 - 5 } & No. & $\%$ & No & $\%$ \\
\hline Age, years & & & & \\
$\geq 60$ & 1,425 & $66.21 \%$ & 55,504 & $71.71 \%$ \\
$<60$ & 627 & $33.79 \%$ & 21,902 & $28.29 \%$ \\
\hline Gender & & & & \\
Males & 1,247 & $57.95 \%$ & 39,366 & $50.86 \%$ \\
Females & 905 & $42.05 \%$ & 38,040 & $49.14 \%$ \\
\hline Primary site & & & & \\
Sigmoid colon & 725 & $33.69 \%$ & 30,102 & $38.89 \%$ \\
Ascending colon & 432 & $20.07 \%$ & 19,981 & $25.81 \%$ \\
Transverse colon & 478 & $22.21 \%$ & 10,194 & $13.17 \%$ \\
Descending colon & 207 & $9.62 \%$ & 6,656 & $8.60 \%$ \\
Hepatic flexure of colon & 147 & $6.83 \%$ & 5,322 & $6.88 \%$ \\
Splenic flexure of colon & 102 & $4.74 \%$ & 3,899 & $5.04 \%$ \\
Overlapping lesion of colon & 61 & $2.83 \%$ & 1,252 & $1.61 \%$ \\
\hline Differentiation & & & & \\
Low grade & 1,305 & $60.64 \%$ & 63,113 & $81.53 \%$ \\
High grade & 847 & $39.36 \%$ & 14,293 & $18.47 \%$ \\
\hline AJCC stage & & & & \\
I & 428 & $19.89 \%$ & 14,605 & $18.87 \%$ \\
IIA & 478 & $22.21 \%$ & 27,549 & $35.59 \%$ \\
IIB & 288 & $13.38 \%$ & 2,100 & $2.71 \%$ \\
IIC & 221 & $10.27 \%$ & 2,187 & $2.83 \%$ \\
IIIA & 245 & $11.38 \%$ & 2,560 & $3.31 \%$ \\
IIIB & 265 & $12.31 \%$ & 18,418 & $23.79 \%$ \\
IIIC & 227 & $10.54 \%$ & 9,987 & $12.90 \%$ \\
\hline
\end{tabular}

Abbreviation: AJCC, american joint committee on cancer.

\section{Determination of the cutoff value of LNR}

In the primary cohort, the median examined lymph node (ELN) was 13.8, ranging from 1 to 82. The median PLN was 2.0, ranging from 1 to 42 . The median LNR (PLN/ELN) value was 0.12 , ranging from 0 to 1 . Xtile (Version 3.6.1) was used to identify a survival-dependent cutoff in LNR values such that the resulting subgroups had significantly different survival courses. After the analysis, the cutoff values of LNR were determined as 0.05 and 0.50 (details are shown in Figure S1). A score of $\geq 0.50$ was taken as the cut-off for high LNR level (mN2), $<0.05$ was regarded as the low LNR level (mN0); thus, the median LNR level was between 0.05 and $0.50(\mathrm{mN} 1)$. For the validation cohort, the median ELN was 17.0 (from 1 to 99). The median PLN was 3.0, ranging from 1 to 98 . The median LNR was 0.26 , ranging from 0.01 to 1.00 . The proportions of $\mathrm{mN} 0, \mathrm{mN} 1$, and $\mathrm{mN} 2$ were $54.45 \%, 25.24 \%$, and $20.31 \%$, respectively.

\section{Prognostic comparison between the $\mathrm{mN}$ stage and the classic $\mathrm{N}$ stage}

In the primary cohort, through the analysis of KaplanMeier curves, LNR values of different levels demonstrated varied duration of survivals $(P<0.001)$ compared with classic $\mathrm{N}$ stage in the primary cohort (Figure 2A and B). The median duration of survival was $70.0(\mathrm{mN} 0), 48.0(\mathrm{mN} 1)$ and $10.0(\mathrm{mN} 2)$ months, respectively. For validation, the cutoff value constructed based on our data showed a similar result, differentiating the survival outcomes in SEER colon cancer patients (Figure $2 \mathrm{C}$ and $\mathrm{D}, P<0.001$ ). The median survival was $44.0(\mathrm{mN} 1), 43.0(\mathrm{mN} 2)$ and 34.0 months $(\mathrm{mN} 3)$, respectively. Comparing to the classic $\mathrm{N}$ stage (C-index: $0.578,95 \% \mathrm{CI}: 0.428-0.893)$, the Cindex of the modified $\mathrm{N}$ stage (C-index: $0.701,95 \% \mathrm{CI}$ : $0.588-0.827)$ was statistically larger $(0.701$ versus $0.578, P<0.001$ in the primary cohort), which demonstrated a preferable performance for discrimination. Similar statistical results can also be determined in the validation cohort.

Preferable C-index has been observed for LNR level compared to classic $\mathrm{N}$ stage. Based on these findings, we further wonder whether there is a difference in the duration of survival between patients without lymph node metastasis (N0) and $0<\mathrm{LNR}<0.05$. Figure $3 \mathrm{~A}$ and $\mathrm{B}$ shows that there is no difference in survival outcomes between the two groups in the primary and validation cohorts, demonstrating that selective patients with smaller values of LNR, even with lymph node metastasis, could have the same prognostic survival outcome as their N0 counterparts. In addition, Figure $3 \mathrm{C}$ and $\mathrm{D}$ demonstrated that in both primary and validation cohorts the patients with $0<\mathrm{LNR}<0.05$ still have better survival outcomes than $\mathrm{mN} 1$ and $\mathrm{mN} 2$ patients. Furthermore, we explore whether this staging system is applicable to patient selection of adjuvant chemotherapy. Chemotherapy status was also recorded. Figure 4 demonstrates survival benefit for adjuvant chemotherapy in each $\mathrm{mN}$ stage in primary (A, B, and $\mathrm{C}$ ) and validation (D, E, and F) cohort. From our analysis, adjuvant chemotherapy shows no survival benefit in $\mathrm{mN} 0$ patients, even in patients with positive $\mathrm{LN}$ metastasis $(P>0.05)$. In contrast, for $\mathrm{mN} 1$ and $\mathrm{mN} 2$ patients, patients receiving chemotherapy demonstrated a better survival outcome than their no chemotherapy counterpart. 

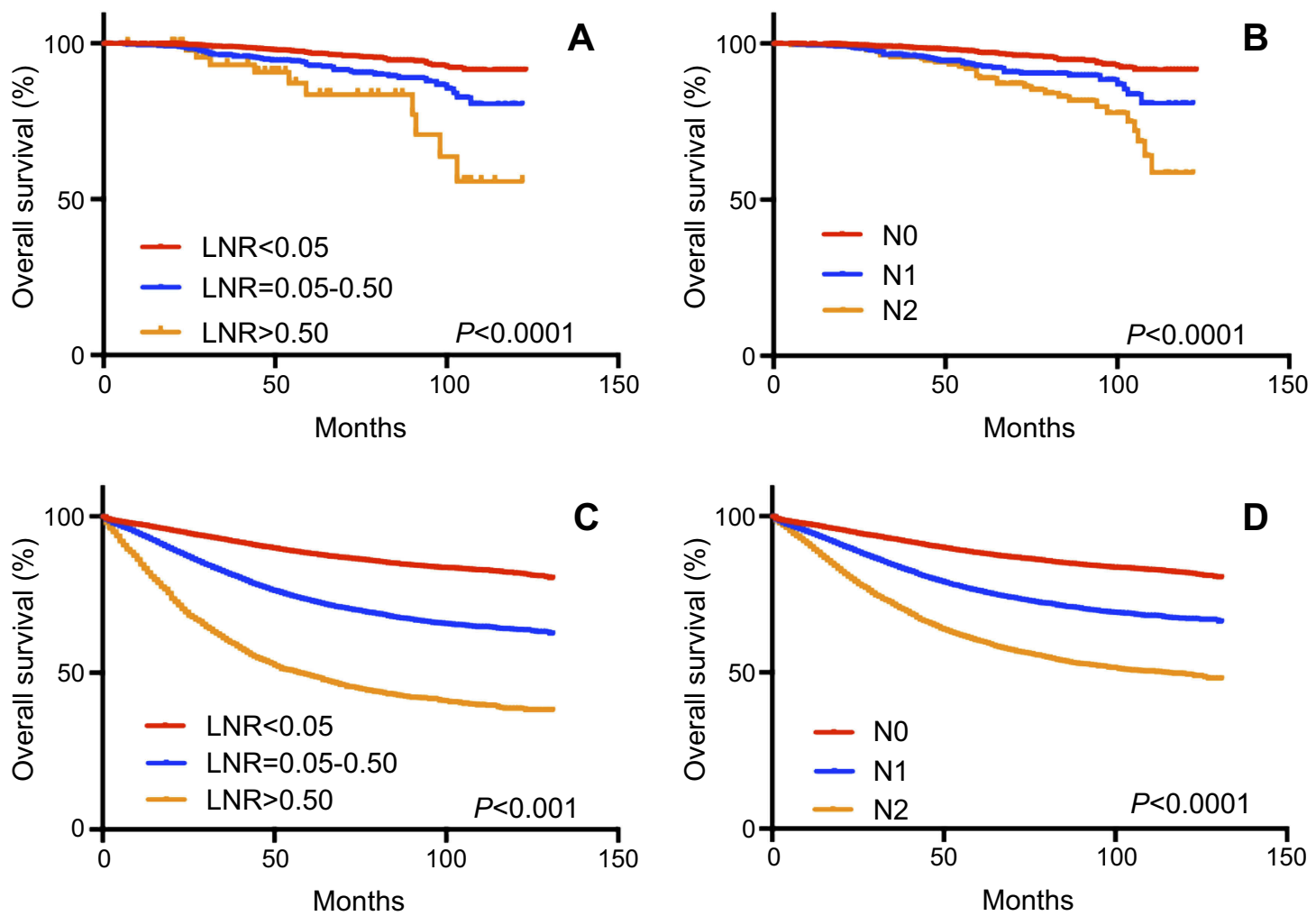

Figure 2 Kaplan-Meier overall survival curves for patients of stratified LNR levels (A and C) and survival outcomes of different classic N levels (B and D). P-values were determined by the log-rank test.

Abbreviation: LNR, lymph node ratio.

\section{Reclassification based on lymph node ratio and tumor stage}

As the AJCC 8th classification divides stage I\II $\backslash I I I$ colon cancer into seven subgroups, I, IIA, IIB, IIC, IIIA, IIIB and IIIC were regarded as the commonly used stage for years. To determine the modified classification for stage I, II and III colon cancer, using mN0, $\mathrm{mN} 1$, and $\mathrm{mN} 2$ to respectively replace $\mathrm{N} 0, \mathrm{~N} 1$, and $\mathrm{N} 2$ in situ, we constructed a new stage based on LNR level and tumor category (Table 2). The modified classification included mI, mIIA, mIIB, mIIC, mIIIA, mIIIB, and mIIIC. In the primary cohort, the proportion of $\mathrm{mI}$, mIIA, mIIB, mIIC, mIIIA, mIIIB, and mIIIC was, respectively, $17.19 \%, 20.21 \%, 15.29 \%, 16.17 \%, 4.65 \%$, $23.61 \%$, and $2.88 \%$ (Figure $5 \mathrm{~A}$ and $\mathrm{B}, P<0.001$ ), the performance of the novel stage was statistically better than the classic stage (C-index: 0.687 versus 0.605 ). SEER data were also retrieved into the classification to validate the newly proposed classification. The proportion of each stage was $18.36 \%, 38.05 \%, 22.4 \%, 4.96 \%$, $0.84 \%, 3.45 \%, 33.54 \%$, and $1.15 \%$, respectively. Figure $5 \mathrm{C}$ and D provided the Kaplan-Meier analysis for the validation of the newly proposed classification with statistical significance $(P<0.001)$.

While the number of ELN and PLN can be affected by the experience of surgeons or pathologists, as well as the operative procedures, we further investigated the value of the proposed classification by using subgroup analysis. Since the SEER database did not provide us with information about the experience of pathologists or surgeons, we divided the patients into two subgroups according to the year of diagnosis (2004-2009 and 2010-2014), based on an assumption that surgeons or pathologists in the latter subgroup might be more experienced than those in the former subgroup. Through our analysis, the ELN in the latter period was statistically higher than the former period (median ELN 18 vs 14, $P<0.001$ ). Based on the proposed classification above, survival curves were also constructed in different groups of diagnosis period. In patients diagnosed between 2004 and 2009, the LNR level and our proposed classification could stratify patients with different survival (Figure S2A and B). Furthermore, in patients diagnosed after 2010, similar results could also be obtained (Figure S3A and B). 

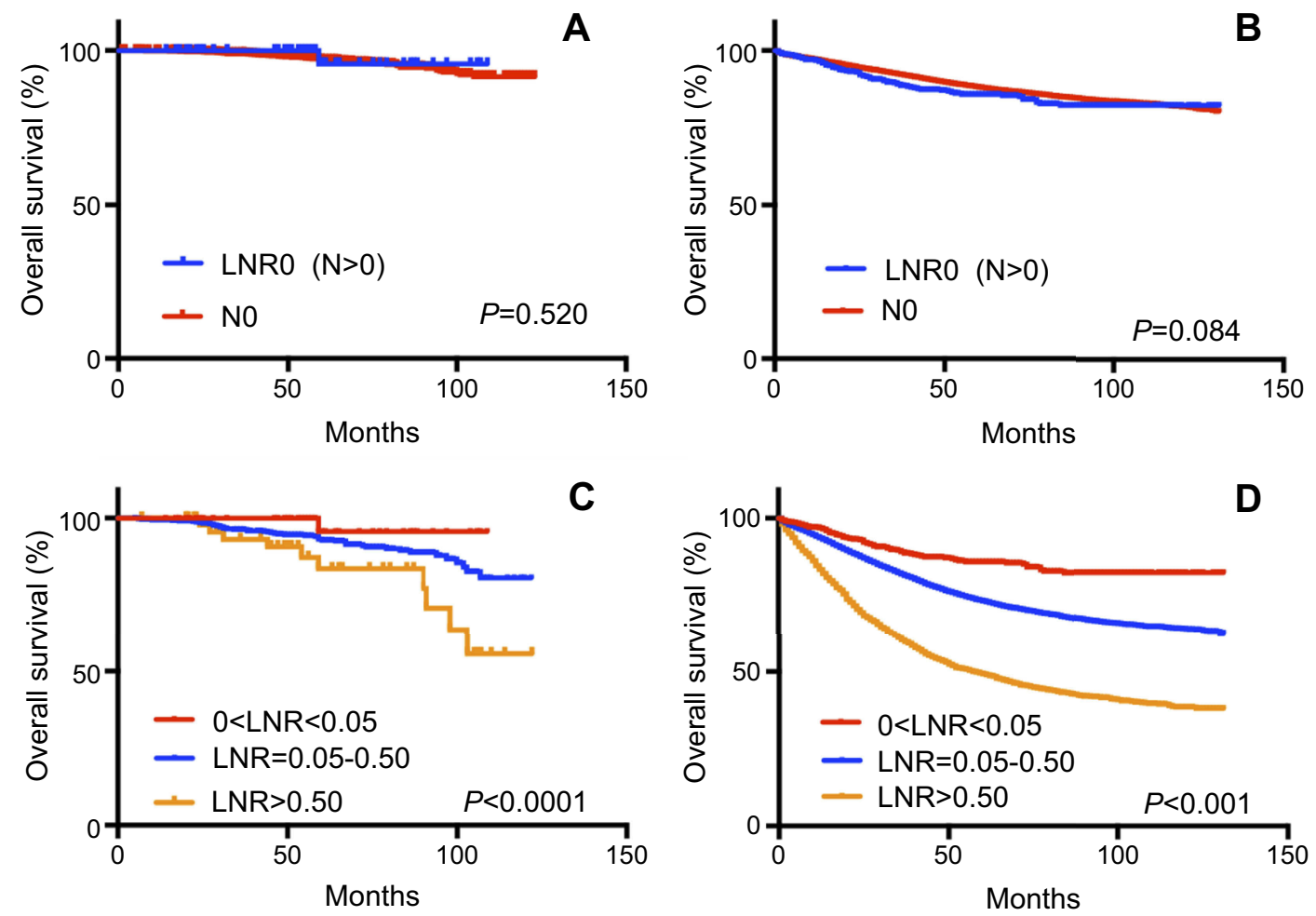

Figure 3 Kaplan-Meier overall survival curves for patients between N0 and $0<\mathrm{LNR}<0.05$ in primary $(\mathbf{A})$ and validation cohort $(\mathbf{B})$. Survival curves among $0<\mathrm{LNR}<0.05$, $\mathrm{mNI}$ and $\mathrm{mN} 2$ were also drawn in primary (C) and validation (D) cohort. P-values were determined by the log-rank test.

Abbreviation: LNR, lymph node ratio.
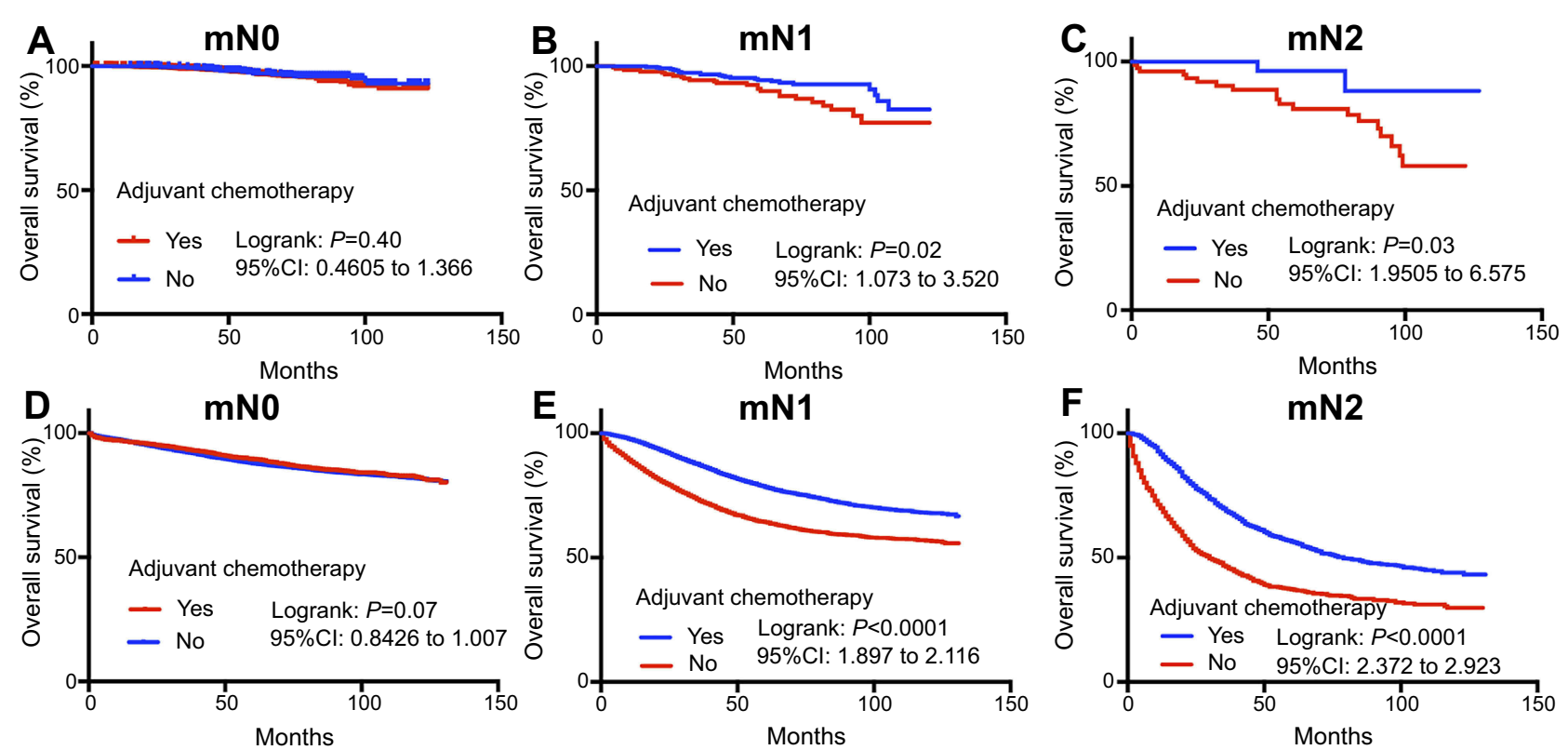

Figure 4 In the primary cohort, the efficacy of postoperative adjuvant chemotherapy is shown for patients of (A) $\mathrm{mNN}$, (B) $\mathrm{mNI}$, and (C) $\mathrm{mN2}$ stage in OS. In the validation cohort, the efficacy of postoperative adjuvant chemotherapy is shown for patients of (D) $\mathrm{mNN}$, (E) $\mathrm{mNI}$, and (F) $\mathrm{mN2}$ stage in OS.

Abbreviations: OS, overall survival; LNR, lymph node ratio. 
Table 2 The AJCC $\mathbf{N}$ staging definitions and our proposed modified lymph node staging definitions based on LNR for stage INIIIII colon cancer

\begin{tabular}{|c|c|c|c|c|c|c|c|c|c|}
\hline \multicolumn{5}{|c|}{ AJCC $\mathbf{N}$ classification } & \multicolumn{5}{|c|}{ Modified lymph node classification based on LNR } \\
\hline \multicolumn{5}{|c|}{ N0: No regional lymph node metastasis } & \multicolumn{5}{|c|}{$\mathrm{mN0}$ : LNR was less than 0.05} \\
\hline \multicolumn{5}{|c|}{ NI: I to 3 regional lymph nodes are positive } & \multicolumn{5}{|c|}{$\mathrm{mNI}$ : LNR was between 0.05 to 0.50} \\
\hline \multicolumn{5}{|c|}{ N2: 4 or more regional lymph nodes are positive } & \multicolumn{5}{|c|}{$\mathrm{mN2}$ : LNR was larger than 0.50} \\
\hline \multicolumn{5}{|c|}{ AJCC 8th stage IIIIIII classification } & \multicolumn{5}{|c|}{ Modified stage IIIIIII classification } \\
\hline & T stage & \multicolumn{2}{|l|}{ N stage } & M stage & & \multicolumn{2}{|c|}{ T stage } & mLN stage & $M$ stage \\
\hline Stage & & & & & Stage & & & & \\
\hline I & $\mathrm{TI}-\mathrm{T} 2$ & No & & MO & $\mathrm{ml}$ & TI-T & $\mathrm{ml}$ & & MO \\
\hline IIA & T3 & No & & MO & mllA & T3 & $\mathrm{ml}$ & & MO \\
\hline IIB & T4a & No & & Mo & mllB & T4a & $\mathrm{ml}$ & & MO \\
\hline IIC & $\mathrm{T} 4 \mathrm{~b}$ & No & & Mo & mIlC & T4b & $\mathrm{ml}$ & & MO \\
\hline \multirow[t]{2}{*}{ IIIA } & TI-T2 & $\mathrm{NI}$ & & Mo & mIllA & TI-T & $\mathrm{ml}$ & & Mo \\
\hline & $\mathrm{TI}$ & N2 & & Mo & & TI & $\mathrm{ml}$ & & MO \\
\hline \multirow[t]{2}{*}{ IIIB } & T3-T4a & NI & & Mo & mllIB & T3-T & $\mathrm{ml}$ & & MO \\
\hline & TI-T3 & N2 & & Mo & & TI-T & $\mathrm{ml}$ & & Mo \\
\hline \multirow[t]{2}{*}{ IIIC } & T3-T4a & N2 & & Mo & mIIIC & T3-T & $\mathrm{ml}$ & & MO \\
\hline & T4b & $\mathrm{NI}-\mathrm{N} 2$ & & MO & & $\mathrm{T} 4 \mathrm{~b}$ & & & MO \\
\hline \multicolumn{5}{|c|}{ AJCC $8^{\text {th }}$ stage IIIIIII classification } & \multicolumn{5}{|c|}{ Modified stage IIIIIII classification } \\
\hline Cohort & \multicolumn{2}{|l|}{ Primary } & \multicolumn{2}{|c|}{ Validation } & & \multicolumn{2}{|c|}{ Primary } & \multicolumn{2}{|c|}{ Validation } \\
\hline Stage & No & $\%$ & No & $\%$ & mStage & No. & $\%$ & No & $\%$ \\
\hline I & 428 & $19.89 \%$ & 14,605 & $18.87 \%$ & $\mathrm{ml}$ & 370 & $17.19 \%$ & $14,2 \mid 4$ & $18.36 \%$ \\
\hline$\| \mathrm{A}$ & 478 & $22.21 \%$ & 27,549 & $35.59 \%$ & mllA & 435 & $20.21 \%$ & 29,455 & $38.05 \%$ \\
\hline IIB & 288 & $13.38 \%$ & 2,100 & $2.71 \%$ & mllB & 329 & $15.29 \%$ & 3,837 & $4.96 \%$ \\
\hline IIC & 221 & $10.27 \%$ & 2,187 & $2.83 \%$ & mllC & 348 & $16.17 \%$ & 650 & $0.84 \%$ \\
\hline IIIA & 245 & $11.38 \%$ & 2,560 & $3.31 \%$ & mIIIA & 100 & $4.65 \%$ & 2,670 & $3.45 \%$ \\
\hline IIIB & 265 & $12.31 \%$ & 18,418 & $23.79 \%$ & mIllB & 508 & $23.61 \%$ & 25,692 & $33.54 \%$ \\
\hline IIIC & 227 & $10.54 \%$ & 9,987 & $12.90 \%$ & mIllC & 62 & $2.88 \%$ & 888 & $1.15 \%$ \\
\hline
\end{tabular}

Abbreviations: AJCC, american joint committee on cancer; LNR, lymph node ratio.

\section{Prognostic nomogram for OS prediction}

Data of both primary and validation cohort patients were included in univariate and multivariate analyses to determine the prognosis-related factors, which is demonstrated in Table 3. From the multivariable analysis of OS, tumor differentiation grade $(P=0.001, \mathrm{HR}=1.144 ; 95 \% \mathrm{CI}$ : 1.112 1.659), modified stage $(P=0.001, \mathrm{HR}=1.078 ; 95 \% \mathrm{CI}$ : $1.010-1.748)$, age level $(P=0.000)$, chemotherapy status $(P=0.002, \mathrm{HR}=0.604 ; 95 \% \mathrm{CI}: 0.442-0.899)$ were regarded as independent risk indicators for tumor OS.

To precisely predict the prognosis in those colon cancer patients including non-TNM risk factors, one accurate prognostic nomogram which integrated age levels, tumor grade, modified stage classification, and chemotherapy status was proposed by multivariate Cox regression models according to the primary set (Figure S4). The Cindex for OS prediction with the formulated nomogram was 0.696 (95\%CI: 0.672-0.738), which was higher than the C-index of the AJCC staging system $(0.605 ; 95 \% \mathrm{CI}$ : $0.485-1.223$ ) in the whole cohort, as is shown in Table 4. Table 4 demonstrates the specific $\mathrm{C}$-index of each prognostic model in primary and validation cohort. The higher C-index, the better predictive accuracy for OS the system achieved. Therefore, the nomogram containing our proposed classification was formulated to predict survival with superior performance. The internal and external validation curves were constructed to validate the performance of the prognosis-prediction model. As shown in Figure S5, the observed probability of 1-, 3-, and 5-year OS in the primary cohort and 1-, 3-, and 5-year OS in the validation 

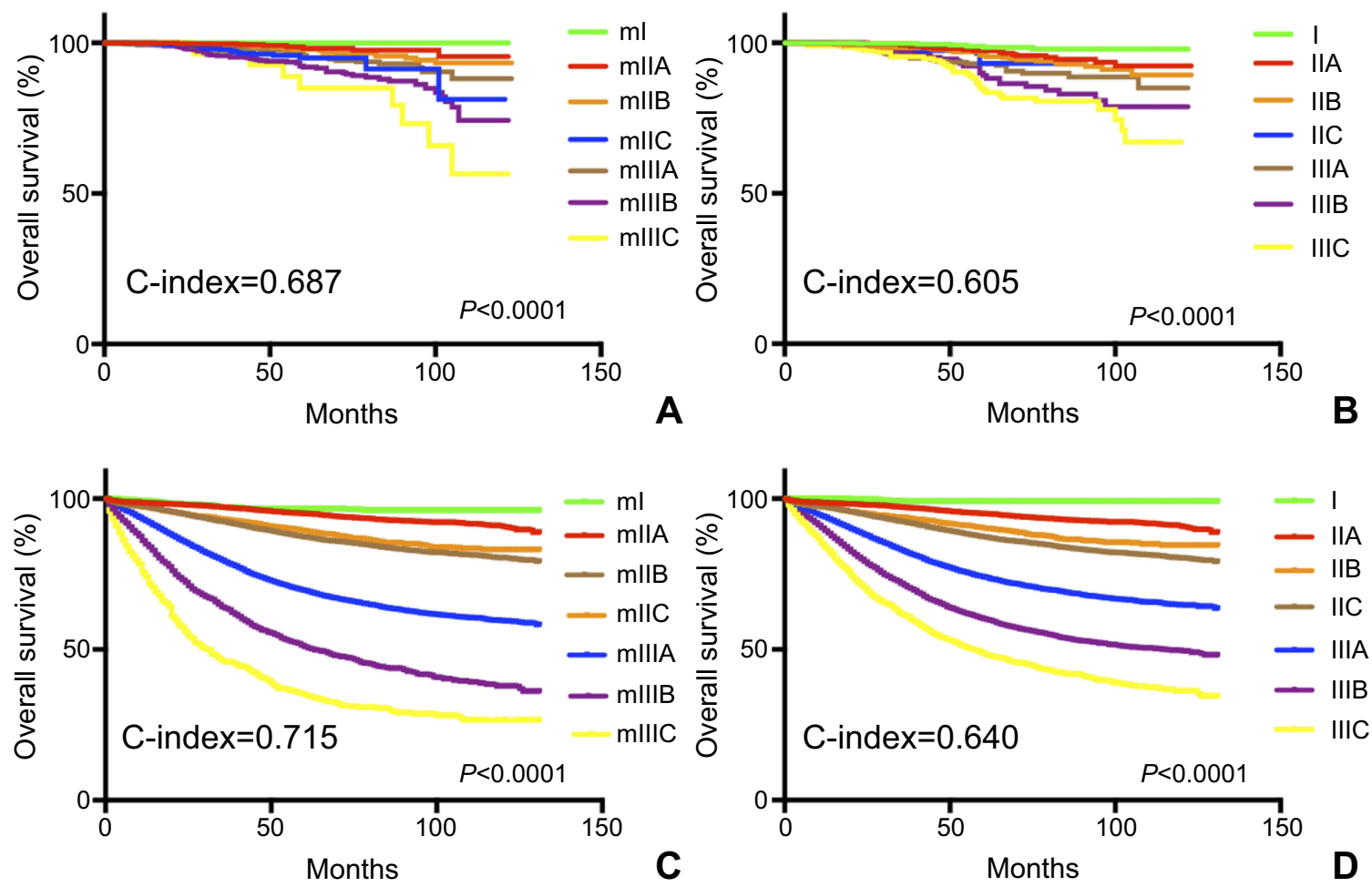

Figure $\mathbf{5}$ Kaplan-Meier overall survival curves for patients of modified classification (A and C) and survival outcomes of different classic AJCC stage levels (B and D). Abbreviation: AJCC, american joint committee on cancer.

cohort showed optimal consistency with the nomogrampredicted OS.

\section{Discussion}

Surgery remains the curative treatment of choice for colon cancer. ${ }^{11}$ However, prognosis in colon cancer is still based on pathological criteria including TNM staging, and LNR has been proposed to improve the prediction of outcomes. ${ }^{10}$ LNR is dependent on optimal retrieval of lymph nodesELN and is defined as the number of PLN divided by the total ELN. ${ }^{12}$ Traditionally, the number of PLN was considered as a determinant factor to determine $\mathrm{N}$ stage. Compared with PLN (N stage), LNR was more independent owing to specific resection range and is more suitable for the clinical analysis in every case. ${ }^{13}$ On the other hand, LNR reflects the number of dissected lymph nodes, which may minimize stage migration and consequently allow more accurate prediction of survival than using the number of metastatic lymph nodes alone. ${ }^{14}$ In addition, with the concept of TME being regarded as the preferred operation in colon cancer and the increase in experiences of surgeons and pathologists, the benefit of the recommended $\mathrm{N}$ stage should be further explored.
In many other kinds of tumor, LNR was found to be a prognostic factor in predicting the survival of patients. ${ }^{15-17}$ In colon cancer, this factor was also well analyzed. ${ }^{18,19}$ It is also obvious that the number of LNR have no clinical value in Stage I and Stage II colon cancer patients with no lymph node metastasis. Previously, $\mathrm{Ali}^{18}$ reported that LNR is a more accurate prognostic factor than lymph node stage in stage III colon cancer patients; however, this study only included 66 patients and has a relatively low volume of the study group. Ramzi ${ }^{19}$ discussed the relationship between the LNR and the resection length, therefore, whether the prognostic classification was based on the ELN and LNR was less explored. Hirotoshi ${ }^{20}$ reported that adding the concept of LNR and location of lymph node metastasis to TNM staging could improve the accuracy of evaluating nodal status in colorectal cancer patients. However, this study included patients with rectal cancer, which had quite different operation standards compared with colon cancer. Mohan ${ }^{10}$ reported that N1/N2 and LNR do not provide additional prognostic value to current staging for OS, with an analysis of only 402 colon cancer patients in one center. Thus, all current research about LNR explored the value in stage III colon cancer. However, some patients with a lower value of LNR may 
Table 3 Characteristics of patients in stage IVIIIII colon cancer patients: univariate and multivariate analysis

\begin{tabular}{|c|c|c|c|c|c|c|c|c|c|c|}
\hline \multirow[t]{2}{*}{ Characteristics } & \multirow{2}{*}{$\begin{array}{l}\text { Patients } \\
\text { (validation) }\end{array}$} & \multicolumn{4}{|c|}{ Overall survival } & \multirow{2}{*}{$\begin{array}{l}\text { Patients } \\
\text { (primary) }\end{array}$} & \multicolumn{4}{|c|}{ Overall survival } \\
\hline & & Uni & $\begin{array}{l}\text { HR }(95 \% \\
\mathrm{Cl})\end{array}$ & Multi & $\begin{array}{l}\text { HR (95\% } \\
\mathrm{Cl})\end{array}$ & & Uni & $\begin{array}{l}\text { HR (95\% } \\
\mathrm{Cl})\end{array}$ & Multi & $\begin{array}{l}\text { HR }(95 \% \\
\mathrm{Cl})\end{array}$ \\
\hline Total & 77,406 & & & & & 2,152 & & & & \\
\hline Gender & & 0.456 & $\begin{array}{l}0.965 \\
(0.953- \\
1.086)\end{array}$ & NA & NA & & 0.797 & $\begin{array}{l}0.712 \\
(0.408- \\
1.247)\end{array}$ & NA & NA \\
\hline Males & 39,366 & & & & & 1,247 & & & & \\
\hline Females & 38,040 & & & & & 905 & & & & \\
\hline Age (years) & & 0.001 & $\begin{array}{l}0.947 \\
(0.886- \\
0.989)\end{array}$ & 0.000 & $\begin{array}{l}0.534 \\
(0.488- \\
0.657)\end{array}$ & & 0.000 & $\begin{array}{l}0.789 \\
(0.768- \\
0.818)\end{array}$ & 0.000 & $\begin{array}{l}0.945 \\
(0.7 \mid 2- \\
0.936)\end{array}$ \\
\hline$\geq 60$ & 55,504 & & & & & 1,425 & & & & \\
\hline$<60$ & 21,902 & & & & & 727 & & & & \\
\hline Differentiation & & 0.000 & $\begin{array}{l}1.201 \\
(1.002- \\
1.349)\end{array}$ & 0.000 & $\begin{array}{l}1.160 \\
(1.082- \\
1.339)\end{array}$ & & 0.000 & $\begin{array}{l}1.326 \\
(1.132- \\
1.645)\end{array}$ & 0.001 & $\begin{array}{l}1.144 \\
(1.112- \\
1.659)\end{array}$ \\
\hline Low grade & 63,113 & & & & & 1,305 & & & & \\
\hline High grade & 14,293 & & & & & 847 & & & & \\
\hline Modified stage & & 0.0000 & $\begin{array}{l}1.566 \\
(1.528- \\
1.605)\end{array}$ & 0.0000 & $\begin{array}{l}1.634 \\
(1.563- \\
1.676)\end{array}$ & & 0.001 & $\begin{array}{l}1.406 \\
(1.054- \\
1.874)\end{array}$ & 0.001 & $\begin{array}{l}1.078 \\
(1.010- \\
1.748)\end{array}$ \\
\hline $\begin{array}{l}\mathrm{ml} \\
\mathrm{mllA} \\
\mathrm{mllB} \\
\mathrm{mllC} \\
\mathrm{mIIIA} \\
\mathrm{mIll} \\
\mathrm{mIlIC}\end{array}$ & $\begin{array}{l}|4,2| 4 \\
29,455 \\
3,837 \\
650 \\
2,670 \\
25,692 \\
888\end{array}$ & & & & & $\begin{array}{l}370 \\
435 \\
329 \\
348 \\
100 \\
508 \\
62\end{array}$ & & & & \\
\hline Chemotherapy & & 0.0000 & $\begin{array}{l}0.525 \\
(0.499- \\
0.542)\end{array}$ & 0.0000 & $\begin{array}{l}0.488 \\
(0.472- \\
0.527)\end{array}$ & & 0.017 & $\begin{array}{l}0.410 \\
(0.347- \\
0.505)\end{array}$ & 0.020 & $\begin{array}{l}0.604 \\
(0.442- \\
0.899)\end{array}$ \\
\hline $\begin{array}{l}\text { Yes } \\
\text { No }\end{array}$ & $\begin{array}{l}24,218 \\
53,188\end{array}$ & & & & & $\begin{array}{l}68 \mid \\
|, 47|\end{array}$ & & & & \\
\hline
\end{tabular}

have the same survival outcomes as the classic N0 (stage I and stage II) patients. Thus, on the one hand, when exploring the prognostic cutoff value of LNR, the factor of no lymph node metastasis should be adjusted, and value of proposed classification should be re-evaluated and validated by another large volume of colon cancer cases; on the other hand, as 0.05 was determined as a cutoff value for LNR, including the data of stage I and II patients can also have similar survival outcome compared with patients with $0<\mathrm{LNR}<0.05$, which can improve prognosis power for this cutoff value.

In this study, 2,152 and 77,406 cases with stage I III IIII colon cancer from one Chinese center and the SEER database were enrolled in the analysis. Through analysis of the clinical characteristics, three subgroups divided based on the cutoff LNR value (mN0, mN1, and $\mathrm{mN} 2$ ) 
were constructed and considered as the modified LNR stage. LNR levels had significant correlations with the duration of survival, as did age level, tumor grade, and $\mathrm{T}$ classification, which are generally consistent with a previous report. ${ }^{21}$ The $\mathrm{mN}$ stage demonstrated good performance for differentiating different various survival outcomes in both primary and validation cohort patients (Figure 2). Retrospectively, duration of survival between the patients without lymph node metastasis (N0) and $0<\mathrm{LNR}<0.05$ was compared, and the statistical difference was not observed in Kaplan-Meier analysis, as is shown in Figure 3, demonstrating that it is necessary to retrieve as many lymph nodes as possible during the operation. The $\mathrm{mN}$ stage can also be a predictive indicator for patients selection of adjuvant chemotherapy. Furthermore, Table 2 shows a modified classification based on LNR and classic AJCC T category in both cohorts. To evaluate the clinical value of this novel classification, the duration of survival demonstrated different survival outcomes in mI, mIIA, mIIB, mIIC, mIIIA, mIIIB, and mIIIC. From the results, we considered that the stage constructed based on LNR was prognostically preferable to the classic $\mathrm{N}$ stage. Classic $\mathrm{N}$ stage did help to inform the prognostic outcome and provide treatment reference in managing the colon cancer. ${ }^{2}$ However, because ELN and PLN are largely influenced by the experience of surgeons or pathologists, as well as the operative procedures, random conditions still exist that some patients with one lymph node metastasis may actually have more lymph nodes metastasis, while some patients who have only one metastasis after retrieving as many as 99 lymph nodes may be prognostically better than their 1 PLN counterpart. Thus, the LNR, as an independent value, can improve the power to determine these patients with better accuracy.
In addition to TNM factors, we also construct a prognostic nomogram containing our modified stage and nonTNM factors such as age level, tumor grade, and adjuvant chemotherapy status. The analysis demonstrated that our proposed model manifested superior predictive value compared to the TNM staging system alone. In addition, the formulated nomogram staging system revealed better performance in risk stratification for the prognosis of patients with resected colon cancer than TNM stage system with a better C-index. All these statistical results were verified in the internal and external validation cohort.

Our study has some limitations. First, since molecular examination results have already been added into the AJCC 8th stage system, several known molecular prognostic factors such as RAS and BRAF were not captured from the SEER database, which may lead to the lack of further analysis; the second limitation is the retrospective nature of this study. In order to confirm the prognosis predictive results, a large control trial may still be required. Additionally, the C-index of the nomogram is good but not excellent. Many other factors can also influence prognosis, and further research is still warranted to improve the accuracy of the nomogram. However, the size of the present study, which we believe to be the largest in stage IVIIVIII colon cancer, provides a comprehensive epidemiologic picture and a more accurate prognostic classification system.

In conclusion, lymphatic metastasis is very common in patients with colon cancer. In colon cancer patients without distant metastasis, LNR was preferable to classic $\mathrm{N}$ stage for discriminating survival outcomes and prediction of chemotherapy. Further, our newly proposed classification based on LNR and AJCC T category effectively demonstrated preferable risk stratification capability. Furthermore, a nomogram including the novel classification and nonTNM factors formulated in this study revealed better discrimination capability to predict 1-, 3- and 5-year OS rates.

Table 4 Discriminatory capabilities of the classification system in primary and validation cohort

\begin{tabular}{|l|l|l|l|l|l|l|}
\hline \multirow{2}{*}{ Variables } & \multicolumn{2}{l|}{ Primary cohort } & \multicolumn{2}{l|}{ Validation cohort } \\
\cline { 2 - 7 } & C-index & $\mathbf{9 5 \%} \mathbf{C I}$ & P-value & C-index & $\mathbf{9 5 \% C l}$ & $\boldsymbol{P}$-value \\
\hline AJCC N stage & 0.578 & $0.428-0.693$ & Reference & 0.601 & $0.528-0.676$ & Reference \\
mLNR stage & 0.701 & $0.588-0.827$ & $P<0.00 I$ & 0.725 & $0.621-0.832$ & $P<0.001$ \\
AJCC IIIIIII classification & 0.605 & $0.485-0.723$ & Reference & 0.640 & $0.502-0.749$ & Reference \\
Modified IIIIIII classification & 0.687 & $0.526-0.832$ & $P<0.00 I$ & 0.715 & $0.649-0.868$ & $P<0.001$ \\
Nomogram & 0.696 & $0.672-0.738$ & NA & NA & NA & NA \\
\hline
\end{tabular}

Abbreviations: AJCC, American Joint Committee on Cancer; C-index, concordance index; LN, lymph node; NA, not available. 


\section{Acknowledgments}

This work was supported by National Natural Science Foundation of China (Grant No. 81602040 and 81472228), Clinical Science and Technology Innovation Project of Shanghai (SHDC12016104) and Shanghai Science and Technology Committee Project (17411951300). Informed consent was obtained by all the patients. The study protocol followed the ethical guidelines of the Declaration of Helsinki and was approved by the Ethical Committee of Zhongshan Hospital of Fudan University. We thank all the doctors and nurses during the treatment process.

\section{Author contributions}

All authors contributed to data analysis, drafting or revising the article, gave final approval of the version to be published, and agree to be accountable for all aspects of the work.

\section{Disclosure}

The authors report no conflicts of interest in this work.

\section{References}

1. Siegel RL, Miller KD, Jemal A. Cancer statistics, 2018. CA Cancer J Clin. 2018;68(1):7-30. doi:10.3322/caac.21442

2. Brody H. Colorectal cancer. Nature. 2015;521(7551):S1. doi:10.1038/ $521 \mathrm{~S} 1 \mathrm{a}$

3. Earle CC, Weiser MR, Ter Veer A, et al. Effect of lymph node retrieval rates on the utilization of adjuvant chemotherapy in stage II colon cancer. J Surg Oncol. 2009;100(7):525-528. doi:10.1002/jso.21373

4. Berger AC, Watson JC, Ross EA, Hoffman JP. The metastatic/examined lymph node ratio is an important prognostic factor after pancreaticoduodenectomy for pancreatic adenocarcinoma. Am Surgeon. 2004;70(3):235-240.

5. Chang GJ, Rodriguez-Bigas MA, Skibber JM, Moyer VA. Lymph node evaluation and survival after curative resection of colon cancer: systematic review. $J$ Natl Cancer Inst. 2007;99(6):433-441. doi:10.1093/jnci/djk092

6. Bianchi PP, Ceriani C, Rottoli M, et al. Laparoscopic lymphatic mapping and sentinel lymph node detection in colon cancer: technical aspects and preliminary results. Surg Endosc. 2007;21(9):1567-1571. doi:10.1007/s00464-006-9152-1

7. Bianchi P, Andreoni B, Rottoli M, Celotti S, Chiappa A, Montorsi M. Technique of sentinel lymph node biopsy and lymphatic mapping during laparoscopic colon resection for cancer. Ecancermedicalscience. 2007;1:60. doi:10.3332/ecancer.2008.60
8. Bembenek AE, Rosenberg R, Wagler E, et al. Sentinel lymph node biopsy in colon cancer: a prospective multicenter trial. Ann Surg. 2007;245(6):858-863. doi:10.1097/01.sla.0000250428.46656.7e

9. Takiyama A, Nozawa H, Ishihara S, et al. Secondary metastasis in the lymph node of the bowel invaded by colon cancer: a report of three cases. World J Surg Oncol. 2016;14(1):273. doi:10.1186/s12957-0161026-y

10. Mohan HM, Walsh C, Kennelly R, et al. The lymph node ratio does not provide additional prognostic information compared with the N1/ N2 classification in Stage III colon cancer. Colorectal Dis. 2017;19 (2):165-171. doi:10.1111/codi.13410

11. Nakai N, Yamaguchi T, Kinugasa Y, et al. Long-term outcomes after resection of para-aortic lymph node metastasis from left-sided colon and rectal cancer. Int $J$ Colorectal Dis. 2017;32(7):999-1007. doi:10.1007/s00384-017-2806-8

12. Wood P, Peirce C, Mulsow J. Non-surgical factors influencing lymph node yield in colon cancer. World J Gastrointest Oncol. 2016;8 (5):466-473. doi:10.4251/wjgo.v8.i5.466

13. Takeshima K, Yamafuji K, Asami A, et al. Successful resection of isolated para-aortic lymph node recurrence from advanced sigmoid colon cancer following 156 courses of FOLFIRI regimen. Case Rep Surg. 2016;2016:4548798. doi:10.1155/2016/4548798

14. Petrelli F, Borgonovo K, Barni S. The emerging issue of ratio of metastatic to resected lymph nodes in gastrointestinal cancers: an overview of literature. Eur J Surg Oncol. 2011;37(10):836-847. doi:10.1016/j.ejso.2011.07.008

15. Rhoads KF, Cullen J, Ngo JV, Wren SM. Racial and ethnic differences in lymph node examination after colon cancer resection do not completely explain disparities in mortality. Cancer. 2012;118(2):469477. doi:10.1002/cncr.26316

16. Persiani R, Cananzi FC, Biondi A, et al. Log odds of positive lymph nodes in colon cancer: a meaningful ratio-based lymph node classification system. World J Surg. 2012;36(3):667-674. doi:10.1007/ s00268-011-1415-x

17. Valsangkar NP, Bush DM, Michaelson JS, et al. N0/N1, PNL, or LNR? The effect of lymph node number on accurate survival prediction in pancreatic ductal adenocarcinoma. $J$ Gastrointest Surg. 2013;17(2):257-266. doi:10.1007/s11605-012-1974-7

18. Zare Mirzaei A, Abdorrazaghi F, Lotfi M, Kazemi Nejad B, Shayanfar N. Prognostic value of lymph node ratio in comparison to lymph node metastases in stage III colon cancer. Iran J Pathol. 2015;10(2):127-135.

19. Amri R, Klos CL, Bordeianou L, Berger DL. The prognostic value of lymph node ratio in colon cancer is independent of resection length. Am J Surg. 2016;212(2):251-257. doi:10.1016/j.amjsurg.2015.10.037

20. Kobayashi H, Enomoto M, Higuchi T, et al. Clinical significance of lymph node ratio and location of nodal involvement in patients with right colon cancer. Dig Surg. 2011;28(3):190-197. doi:10.1159/ 000323966

21. Lykke J, Jess P, Roikjaer O; Danish Colorectal Cancer Group. A high lymph node yield in colon cancer is associated with age, tumour stage, tumour sub-site and priority of surgery. Results from a prospective national cohort study. Int $J$ Colorectal Dis. 2016;31 (7):1299-1305. doi:10.1007/s00384-016-2599-1 


\section{Supplementary materials}

A

\begin{tabular}{|c|c|}
\hline Rank & Range \\
\hline O to 18 & 0.00 thru 0.05 \\
\hline 19 to 104 & 0.05 thru 0.50 \\
\hline 105 to 129 & 0.52 thru 1.00 \\
\hline Oto 129 & 0.00 thru 1.00 \\
\hline & \\
\hline & \\
\hline & \\
\hline & \\
\hline & \\
\hline & \\
\hline & \\
\hline
\end{tabular}

\begin{tabular}{|l|c|c|}
\hline \hline Chi-Sq Hi/Mid/Lo & 28.5945 & Max: $<0.000$ \\
\hline Lo vs Mid & 14.6893 & \\
\hline Mid vs Hi & 4.4284 & \\
\hline Lo vs Hi & 21.0663 & \\
\hline Relative Risk 1 vs 2 vs 3 & $1.00 / 2.23 / 4.91$ & \\
\hline & & \\
\hline & & \\
\hline & & \\
\hline & & \\
\hline & & \\
\hline & & \\
\hline & & \\
\hline
\end{tabular}

B

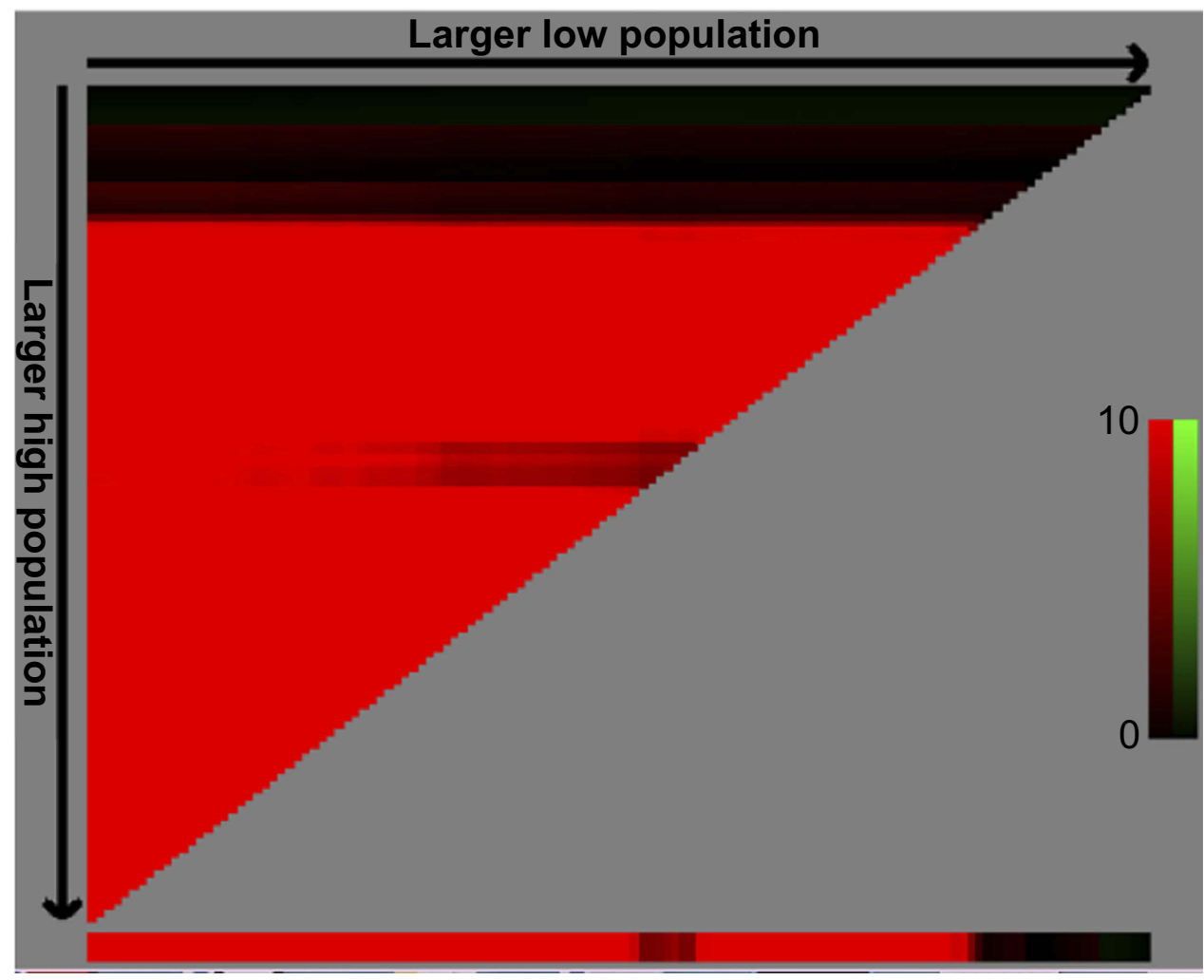

Figure SI A demonstration of the result from the analysis of $\mathrm{X}$-tile.
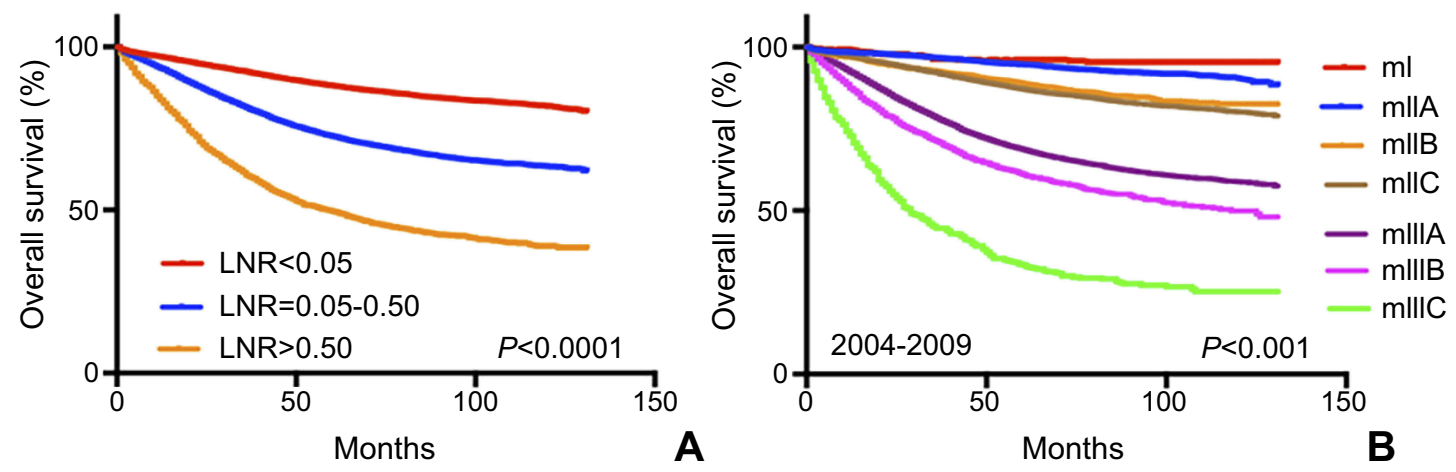

Figure S2 SEER patients diagnosed between 2004 and 2009, (A) patients with LNR $>0.50$ had significantly worse prognosis than patients with LNR $<0.05$ and patients with LNR between 0.05 and $0.50(P<0.000 \mathrm{I})$, and $(B)$ survival analysis showed that modified stage $\mathrm{ml}, \mathrm{mllA}, \mathrm{mllB}, \mathrm{mllC}$, mllIA, mlllB, and mllIC had stratified survival ( $p<0.000 \mathrm{I})$. Abbreviations: LNR, lymph node ratio; SEER, Surveillance, Epidemiology, and End Results. 

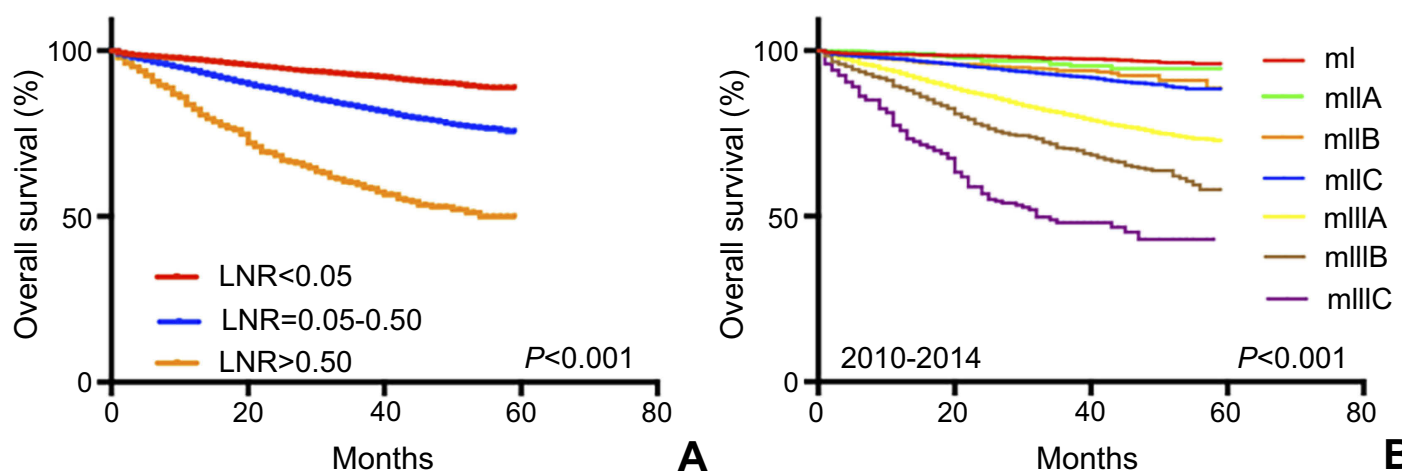

Figure S3 SEER patients diagnosed after 20I0, (A) patients with LNR $>0.50$ had significantly worse prognosis than patients with LNR $<0.05$ and patients with LNR between 0.05 and $0.50(P<0.00 \mathrm{I})$, and $(B)$ survival analysis showed that modified stage $\mathrm{ml}$, mllA, mllB, mllC, mllIA, mlllB, and mlllC had stratified survival $(p<0.00 \mathrm{I})$.

Abbreviations: LNR, lymph node ratio; SEER, Surveillance, Epidemiology, and End Results.

Points

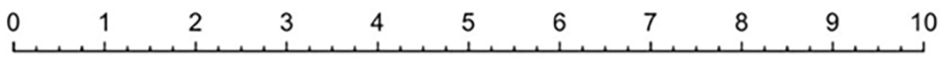

Agelevel

1

modifiedstage

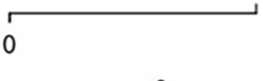

modifiedstage

$\begin{array}{lll} & 1 \\ 1 & 4\end{array}$

Grade

Chemo

3

足

Total Points

1

\begin{tabular}{llllllllllll}
\hline 0 & 2 & 4 & 6 & 8 & 10 & 12 & 14 & 16 & 18 & 20
\end{tabular}

1-year survival

\begin{tabular}{|c|c|c|}
\hline & 0.9 & 0.85 \\
\hline
\end{tabular}

3-year survival

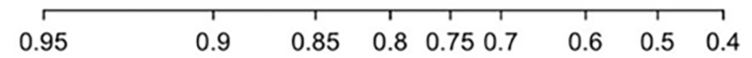

5-year survival

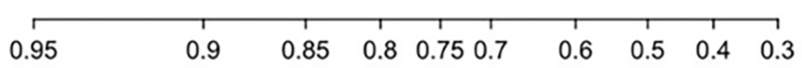

Figure S4 Nomogram to predict OS of patients with AJCC stage IIIIIII colon cancer. To validate the nomogram, the sum of each predictor point was charted on the total points axis. The 1-, 3-, and 5-year OS rates were estimated by plotting a straight vertical line from the charted total points axis to the same OS rate axis. For the "Age level" line, I indicates " $\geq 60$ years" old and 0 indicates " $<60$ years old". For the "Chemo" line, I refers to "adjuvant chemotherapy performed" and 0 refers to "not performed". For the "Grade" line, 0, I, 2 and 3 refer to the well-differentiated, median-differentiated, poorly differentiated and undifferentiated, respectively. For the "modified stage" line, I to 7 separately refer to $\mathrm{ml}$ to $\mathrm{mIIIC}$ stage.

Abbreviations: AJCC, American Joint Committee on Cancer; OS, overall survival. 

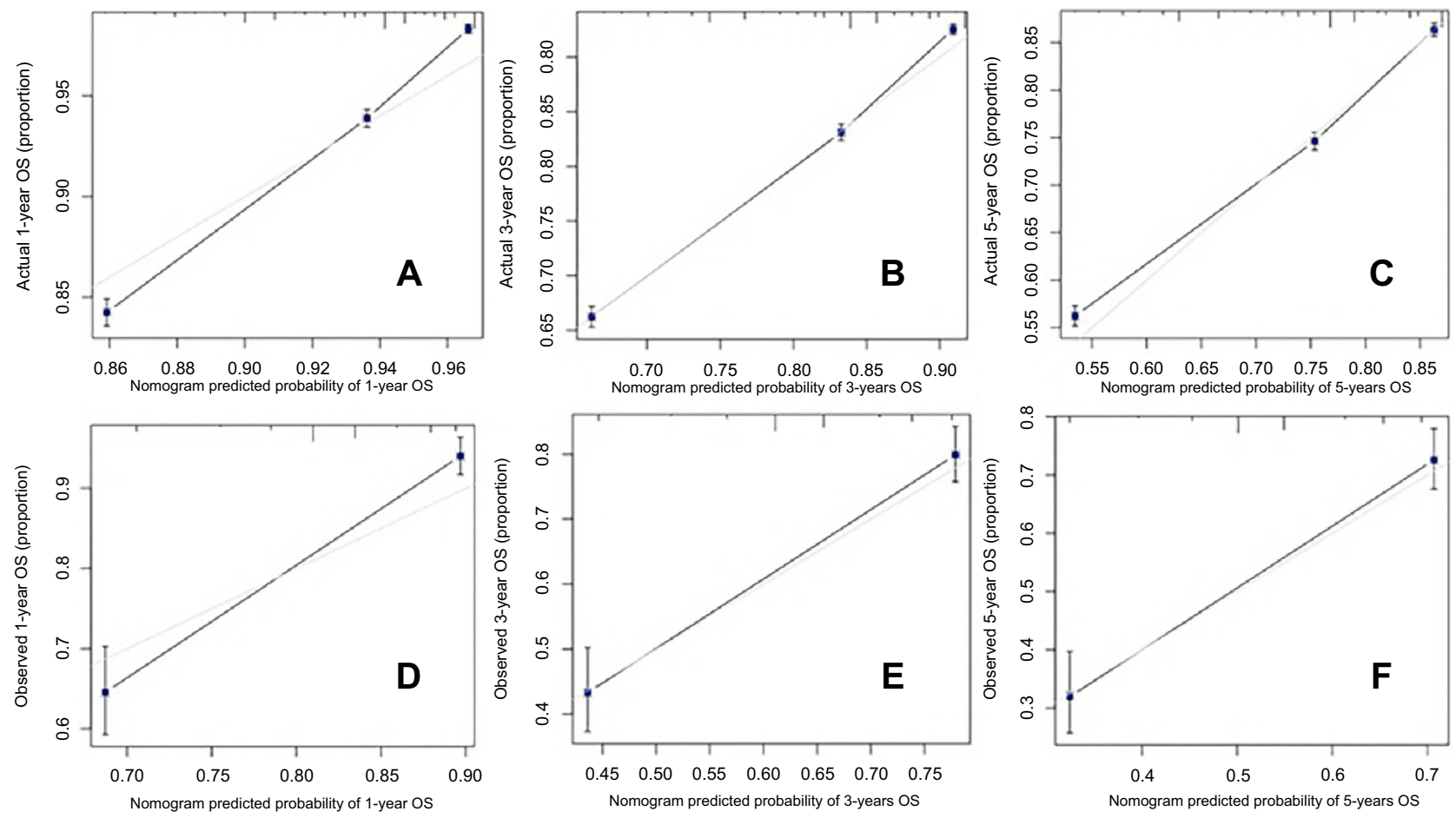

Figure S5 Calibration curves for the nomogram. The calibration curves predict OS at I year (A), 3 years (B), and 5 years (C) in the primary cohort and at I year (D), 3 years $(\mathbf{E})$ and 5 years $(\mathbf{F})$ in the validation cohort.

Abbreviation: OS, overall survival.

Cancer Management and Research

Dovepress

\section{Publish your work in this journal}

Cancer Management and Research is an international, peer-reviewed open access journal focusing on cancer research and the optimal use of preventative and integrated treatment interventions to achieve improved outcomes, enhanced survival and quality of life for the cancer patient.

The manuscript management system is completely online and includes a very quick and fair peer-review system, which is all easy to use. Visit http://www.dovepress.com/testimonials.php to read real quotes from published authors. 